\title{
An isothermal based recombinase polymerase amplification assay for rapid, sensitive and robust indexing of citrus yellow mosaic virus
}

\author{
P. V. KUMAR ${ }^{1}$, S. K. SHARMA², N. RISHI ${ }^{3}$, D. K. GHOSH ${ }^{4}$, V. K. BARANWAL ${ }^{*}$
}

\begin{abstract}
${ }^{1}$ Advanced Centre for Plant Virology, Division of Plant Pathology, ICAR-Indian Agricultural Research Institute, New Delhi 110012, India; ${ }^{2} \mathrm{ICAR}$ Research Complex for NEH Region, Manipur Centre, Imphal 795004, India; ${ }^{3}$ Amity Institute of Virology and Immunology, Amity University, Noida-201303, India; ${ }^{4}$ ICAR-Central Citrus Research Institute, Nagpur 440033, India
\end{abstract}

\begin{abstract}
Summary. - Management of viral diseases relies on definite and sensitive detection methods. Citrus yellow mosaic virus (CYMV), a double stranded DNA virus of the genus Badnavirus, causes yellow mosaic disease in citrus plants. CYMV is transmitted through budwood and requires a robust and simplified indexing protocol for budwood certification programme. The present study reports development and standardization of an isothermal based recombinase polymerase amplification (RPA) assay for a sensitive, rapid, easy, and cost-effective method for detection and diagnosis of CYMV. Two different oligonucleotide primer sets were designed from ORF III (coding for polyprotein) and ORF II (coding for virion associated protein) regions of CYMV to perform amplification assays. Comparative evaluation of RPA, PCR and immuno-capture recombinase polymerase amplification (IC-RPA) based assays were done using purified DNA and plant crude sap. CYMV infection was efficiently detected from the crude sap in RPA and IC-RPA assays. The primer set used in RPA was specific and did not show any crossamplification with banana streak MY virus (BSMYV), another Badnavirus species. The results from the present study indicated that RPA assay can be used easily in routine indexing of citrus planting material. To the best of our knowledge, this is the first report on development of a rapid and simplified isothermal detection assay for CYMV and can be utilized as an effective technique in quarantine and budwood certification process.
\end{abstract}

Keywords: citrus yellow mosaic virus; RPA; PCR; IC-RPA

\section{Introduction}

Citrus is an important and perennial fruit crop cultivated worldwide and it is known to be affected by large number of viruses and virus-like pathogens. Citrus yellow mosaic virus (CYMV), a member of the family Caulimoviridae, the genus Badnavirus known to infect citrus varieties such as sweet orange, mandarin and acid lime in India. It causes severe losses in citrus production and affects quality of the fruit (Ahlawat, 2000). Badnaviruses are pararetroviruses

*Corresponding author. E-mail: vbaranwal2001@yahoo.com; phone: +91-11-25843113.

Abbreviations: $\mathrm{BSMYV}=$ banana streak MY virus; $\mathrm{CYMV}=$ cit rus yellow mosaic virus; IC-RPA = immuno-capture recombinase polymerase amplification; RPA $=$ recombinase polymerase amplification characterized by non-enveloped bacilliform particles measuring $30 \times 120-150 \mathrm{~nm}$, and has double stranded genome of 7.5-8.0 kb (King et al., 2012). CYMV causes yellow mosaic disease, characterized by yellow mosaic and yellow vein flecking symptoms on the leaves of diseased citrus trees (Ahlawat et al., 1996).

At present, nucleic-acid based techniques like PCR (Baranwal et al., 2005), DNA probes (Korsten et al., 1993), dot-blot hybridization (Borah et al., 2008), immuno based diagnostics using antisera produced against purified virus (Ahlawat et al., 1996) are available for routine detection of CYMV but all these methods are cumbersome, require skilled and trained personnel, well equipped sophisticated lab facilities and are time consuming. In recent times plant virus diagnostics have seen a paradigm shift towards development of on-site isothermal diagnostics. Loop mediated isothermal amplification (LAMP) assay was employed in 
detecting plant viruses, but has limitations in terms of using purified nucleic acid (DNA or RNA) as template. It involves use of 4-6 primer sets which are difficult to design and further increase the cost of assay. LAMP also had issues in regarding yielding reliable results as it generates multimeric products (Bakheit et al., 2008). As an alternate to the techniques available, a simplified isothermal based amplification technique, recombinase polymerase amplification (RPA) has been recently developed and successfully employed in detecting a few plant viruses from the crude sap (Kapoor et al., 2017; Londono et al., 2016; Mekuria et al., 2014; Silva et al., 2015; Zhang et al., 2014). RPA assay can be carried out at $37^{\circ} \mathrm{C}$ in a dry bath or an incubator and there is no requirement of expensive thermal cycler. In RPA, detection of virus is achieved by addition of enzyme recombinase which assists primer extension, strand displacing polymerase ( $3^{\prime}$ extension at low temperatures $25-42^{\circ} \mathrm{C}$ ) and protein like single-stranded binding protein (SSB) for stabilization of displaced strands (Londono et al., 2016). Present study, for the first time portraits the development of rapid and sensitive assay for detection of CYMV using RPA technology and its comparative evaluation with PCR and IC-RPA.

\section{Materials and Methods}

Samples. Yellow mosaic disease affected citrus plants were collected from Southern (Andhra Pradesh, Karnataka states) India and maintained in the greenhouse facility of Advanced Centre for Plant Virology, ICAR-Indian Institute of Agricultural Research Institute, New Delhi (ACPV-IARI), and used as source material in the present study. Both symptomatic and asymptomatic plants were used in RPA, PCR, and IC-RPA assays.

Template preparation. Total DNA (purified DNA) was extracted from $100 \mathrm{mg}$ of leaf tissue using GeneJET Plant genomic DNA purification mini kit (Thermo Scientific, EU, Lithuania) following manufacturer's protocol. $40 \mu \mathrm{l}$ of DNA was eluted from each sample and quantified using NanoDrop ${ }^{\mathrm{TM}} 1000$ spectrophotometer (Thermo Scientific, USA). Crude sap was extracted from $100 \mathrm{mg}$ of leaf tissue grinded in $400 \mu$ of general extract buffer (GEB, Agdia, USA) followed by centrifugation at 12,000 rpm for $2 \mathrm{~min}$. Supernatant was used as template in RPA assay. Likewise, crude sap and DNA was extracted from healthy plants and used as negative control.
Primer design and PCR assays. Two different sets of primers (Table 1) were designed from the ORF II and ORF III regions of CYMV from the sequences available in NCBI database (GenBank Acc. No. DQ875213). The designed primers were up to 30-35 nucleotide long as per manufacturer's instructions (TwistDx, UK), and rich in GC at 3'end and with pyrimidine at 5' end; with amplicon length less than 500 bp (Pipenburg et al., 2006; Euler et al., 2013). PCR was carried out with standard thermal cycling conditions with an initial denaturation at $94^{\circ} \mathrm{C}$ for $3 \mathrm{~min}$ and a final extension at $72^{\circ} \mathrm{C}$ for $10 \mathrm{~min}$. Amplification cycles were as follows: 30 cycles of denaturation at $94^{\circ} \mathrm{C}$ for $30 \mathrm{~s}$, annealing at $67.5^{\circ} \mathrm{C}$ for $30 \mathrm{~s}$, and extension at $72^{\circ} \mathrm{C}$ for $30 \mathrm{~s}$. PCR products were separated on $1.6 \%$ agarose gel and stained with ethidium bromide.

Recombinase polymerase amplification (RPA). RPA was performed using the designed primers by following manufacturers protocols described in Twist Amp basic kit (TwistDx, UK) with a total reaction volume of $25 \mu \mathrm{l}$. $50 \mu \mathrm{l}$ reaction mixture was prepared, added to freeze dried pellet, distributed into equal halves in two separate tubes followed by addition of $1 \mu$ of crude sap as template and finally $1.25 \mu \mathrm{l}$ of magnesium acetate $(280 \mathrm{mmol} / \mathrm{l})$ was added and properly mixed without causing any air bubbles. Reaction was incubated at $37^{\circ} \mathrm{C}$ for $30 \mathrm{~min}$ in a dry bath and heat inactivated at $65^{\circ} \mathrm{C}$ for $10 \mathrm{~min}$ prior to agarose gel electrophoresis.

Comparison of sensitivity of detection by RPA and PCR. The sensitivity of RPA was compared with PCR using the primer set RPA F2/R2. The detection sensitivity level of RPA and PCR was carried out using serial dilutions of genomic DNA and crude leaf extracts in the respective assays. For PCR $100 \mathrm{ng} / \mu \mathrm{l}$ of purified DNA was used as a template and serially diluted up to $10^{-6}$-fold using sterile distilled water. Likewise, crude leaf extracts ( $100 \mathrm{mg}$ of tissue $/ 400 \mu \mathrm{l}$ ) were serially diluted up to $10^{-6}$-fold using GEB. All the diluted templates were evaluated by PCR and RPA assay. Specificity of RPA was analysed by cross reaction assay with the crude sap and purified DNA extracted from banana infected with banana streak MY virus (BSMYV) a member of the genus Badnavirus.

Immuno-capture-RPA. IC-RPA was carried out by using polyclonal antisera (raised against CYMV using recombinant virion associated protein gene with histidine tag, (Kumar et al., 2018) at a dilution of 1:100 (diluted with $100 \mu \mathrm{l} 1 \mathrm{x}$ coating buffer with $2 \%$ PVP- polyvinyl pyrrolidone). The crude antiserum was coated $(25 \mu \mathrm{l}$ ) on to a $0.2 \mathrm{ml}$ sterile polypropylene PCR tubes (Axygen, USA) and incubated overnight $\left(4^{\circ} \mathrm{C}\right)$. Tubes washed thrice with $1 \mathrm{x}$ PBST and coated with $0.8 \mu$ l crude sap extracted from citrus plants (using grinding buffer containing $100 \mathrm{ml} \mathrm{1x}$ PBST, 0.2 g sodium

Table 1. Primers used for detecting CYMV in present study

\begin{tabular}{llll}
\hline Primer & Sequence & Target region & Product size \\
\hline RPA F1 & 5' CAGTCCATCACTTGGATTTGTTAACCCGGAGG 3' & ORF II & \multirow{2}{*}{ 209 bp } \\
RPA R1 & 5' CGTCAGGTAAGGCTGTTGTTGATGAGCCTTGC 3' & & \\
RPA F2 & 5'GCTTACCTGTGATTCTGTCAAGCATATAGTCC 3' & ORF III & 200 bp \\
RPA R2 & 5'CCTAGGGCAAACACCAATAATGTTCCCTGG 3' & \\
\hline
\end{tabular}


sulphite, 2 g PVP) infected with CYMV and incubated at $37^{\circ} \mathrm{C}$ for $3 \mathrm{~h}$. Tubes were washed again as mentioned above and IC-RPA was carried out directly in the tubes containing trapped virus particles from the sap preparations of infected leaves.
RPA validation. PCR amplification was performed with both genomic DNA and crude sap extract from the CYMV infected plants for validating RPA assay with PCR and IC-RPA. About ten symptomatic plants of different citrus varieties like sweet orange (a)

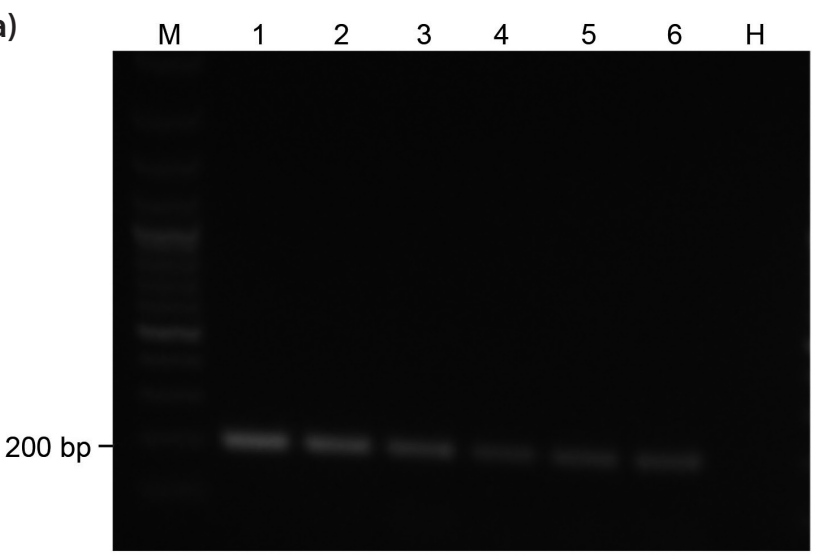

(b)

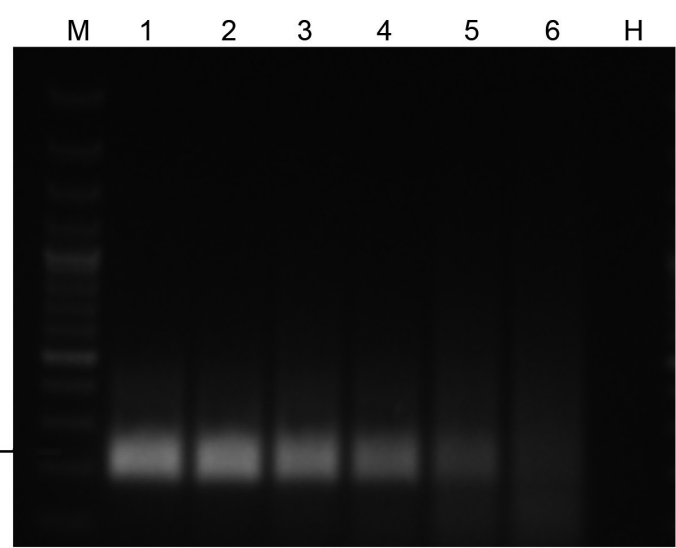

Fig. 1

Agarose gel electrophoresis showing sensitivity analysis of RPA with PCR

(a) PCR amplification using purified DNA as template with 10-fold serial dilutions, (b) RPA amplification using crude leaf sap extract as template with 10-fold serial dilutions. Lane M, Thermoscientific O'generuler 100 bp ladder; lane 1-6, serial dilutions of positive control $\left(10^{-1}-10^{-6}\right)$.

(a)

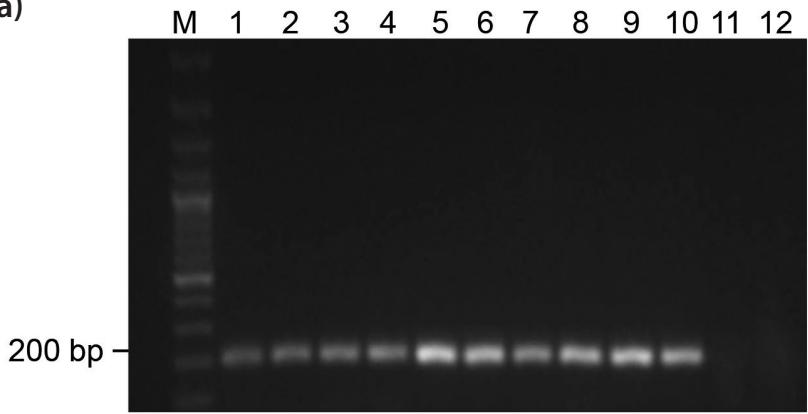

(c)

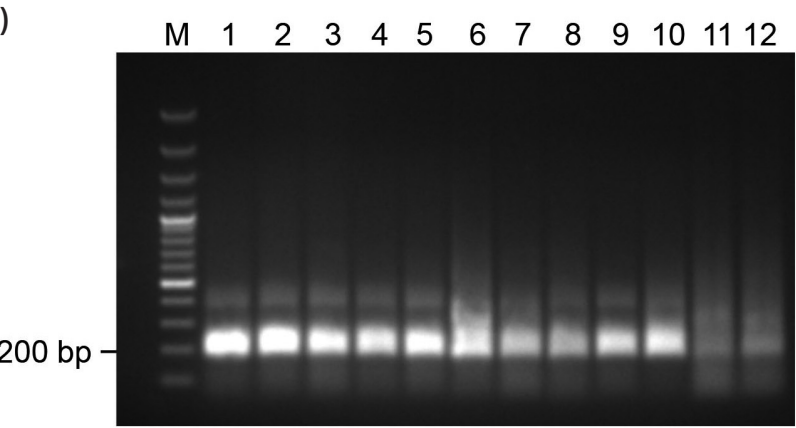

(b)

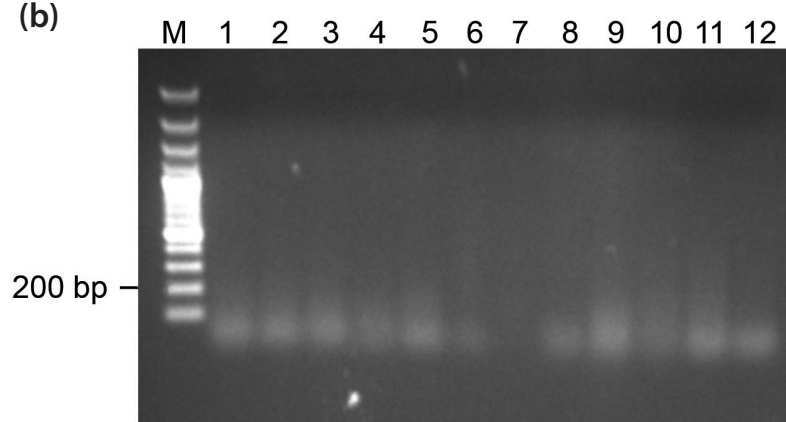

(d)

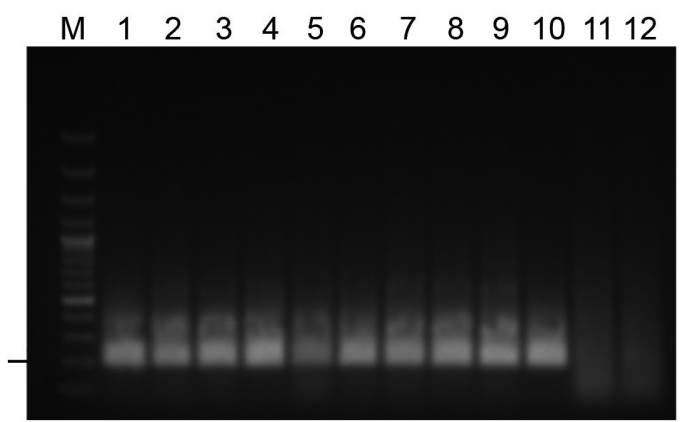

Fig. 2

Agarose gel electrophorsis showing different assays performed

(a) PCR assay with DNA as template, (b) direct binding PCR with crude sap as template, (c) RPA with crude sap as template, (d) immuno-capture RPA (IC-RPA) with crude sap as template. Amplicon size of $200 \mathrm{bp}$. Lane M, Thermoscientific O'generuler 100 bp ladder; lane 1-9, different field samples; lane 10 positive control; lane 1, BSMYV infected banana plant; lane 12, healthy control. 
(3 samples), kinnow (3 samples), mandarin (2 samples), and acid lime (2 samples), one healthy citrus (free from CYMV infection), and banana infected with BSMYV were taken for validation.

\section{Results}

\section{Primer specificity}

The primers designed in the present study were first analysed by performing PCR and RPA assay. In PCR, using purified DNA as template positive amplification with desired amplicon sizes of $209 \mathrm{bp}$ (with primer pairs RPA F1/R1) and 200 bp (with primer pairs F2/R2) was observed. In RPA assay, when crude sap was used as template, amplification was observed only with primer pairs RPA F2/R2, however, when DNA was used as template, reactions with both primer pairs were positive. As the major aim of our study was to detect virus from crude sap therefore, in all further experiments, primer pair RPA F2/R2 was used. The RPA amplicons derived from RPA F2/R2 primer sets were purified from gel and sequenced at Europhins genomics (India). The BLASTn sequence analysis of purified RPA product revealed 99\% identity with the ORF III region of CYMV sequence DQ875213.

\section{Sensitivity of RPA}

The sensitivity and detection limits of RPA and PCR was compared using ten-fold dilutions of purified genomic DNA and crude leaf sap extracts. PCR performed with primer pairs RPA F2/R2, using genomic DNA as a template, gave positive amplification at the dilution of $10^{-6}$ (Fig. 1a), whereas RPA assay performed with crude sap as a template gave positive amplification at the dilution of $10^{-5}$ (Fig. 1b). Amplification was not observed in healthy samples in any of the two assays.

\section{Validation of RPA}

Crude sap and genomic DNA from 10 different citrus samples was extracted and validation of RPA assay and ICRPA was done. Comparison of PCR using purified DNA as template (Fig. 2a), with crude sap as template (Fig. 2b), RPA assay with crude sap as template (Fig. 2c), and IC-RPA assay with crude sap as template (Fig. 2d) was performed by employing the primer pair RPA F2/R2. The expected amplicon size of 200 bp was observed in all the assays except in PCR where crude sap was used as template. Amplification was not observed in healthy control samples in any assay. Crossreactivity of RPA assay was analysed by using purified DNA and crude leaf sap extracted from BSMYV infected banana leaf sample (Fig. 2a-d). Cross-amplification was not observed in any assay. These results confirmed the RPA assay and the primers for detection of CYMV as highly specific and could be successfully employed in detecting CYMV infections.

\section{Discussion}

CYMV is one of the major limiting factors in citrus production in India (Ahlawat et al., 2000) and generally known to be propagated through infected budwoods. DNA from buds, bark, and leaf tissues of citrus varieties of sweet orange, Pummelo, and Rangpur lime infected with CYMV has been used for detection in PCR. The standard PCR methods reported for detection of CYMV, have limitations in terms of applicability in the resource poor laboratories as it requires thermal cyclers and involve cumbersome procedure of nucleic acid isolation. Therefore, development of simplified, rapid and sensitive diagnostic method for CYMV is highly desirable. Present study, successfully demonstrated the development of a rapid and simplified RPA based assay and its application in specific detection of CYMV.

RPA is an inexpensive experiment as it uses plant crude sap as a template for detecting the virus infection, rather than the need to have purified DNA or RNA as in case of PCR. As the isothermal amplification is carried out at uniform and low temperatures $\left(37-42^{\circ} \mathrm{C}\right)$ use of expensive thermal cyclers is not required (Londono et al., 2016) which makes it an assay of choice in resource poor laboratories.

The primer pair RPA F1/R1 did not yield any amplification product from crude sap even after modifying the concentrations of the reaction mixture, hence all the assays were performed using primer pair RPA F2/R2 to detect the virus from plant crude sap. In PCR, successful amplification of CYMV was observed only when purified DNA was used as a template, however when crude sap was used as template amplification failed. The sensitivity limit of PCR using purified DNA as a template was at dilution $10^{-6}$ whereas that of RPA using crude sap as a template was already at dilution $10^{-5}$. Another benefit of the RPA is its demand for less material for the template (60-80 mg tissue) compared to PCR which requires DNA from $100 \mathrm{mg}$ tissue. IC-RPA developed in present study could successfully trap the CYMV particles (overnight coating with antiserum) and yielded positive amplification. Although being specific and sensitive method, IC-RPA is time consuming, requires virus specific high titre antisera and therefore, cannot be used in routine indexing of CYMV. RPA is recommended as a simplified and fast method for indexing viral infections. RPA based detection (both assay and visualization of products) can be completed within an hour which indicates its applicability as quick, simplified and robust detection method for CYMV.

RPA is used as a cost-effective method for detecting viruses (Londono et al., 2016). The overall carrying cost of the experiment is less than carrying out PCR based thermal 
amplification (involves use of commercial kit for nucleic acid extraction, thermal cycler, and reagents). RPA has significantly reduced man-power and time in comparison with PCR based methods (Silva et al., 2015). The rapid kinetics and its simplicity attributes of RPA assay makes it as an ideal technique and more advantageous over other molecular diagnostic tools.

To the best of our knowledge, this is the first report on development of RPA and IC-RPA based assays for robust detection of CYMV. The results from the present study showed that RPA can be successfully used in quarantine process for screening large amount of samples, screening in vitro produced tissue culture plants, screening for resistance against CYMV and in budwood certification programmes.

Acknowledgments. We thank ICAR - Outreach project to bear financial assistance for carrying out experiments, Head, Division of Plant Pathology and Director of ICAR-Indian Agricultural Research Institute, New Delhi for providing necessary lab facilities.

\section{References}

Ahlawat YS, Pant RP, Lockhart BEL, Srivastava M, Chakraborty NK, Verma A (1996): Association of a badnavirus with citrus mosaic mosaic disease in India. Plant Dis.80, 590-592. https://doi.org/10.1094/PD-80-0590

Ahlawat YS (2000): Yellow mosaic. In Timmer P, Garnsey SM, Graham T (Eds): Compendium of Citrus Diseases. 2nd ed. APS Press, pp. 63-64.

Bakheit MA, Torra D, Palomino LA, Thekisoe OMM, Mbati PA, Ongerth J, Karanis P (2008): Sensitive and specific detection of Cryptosporidium species in PCR-negative samples by loop-mediated isothermal DNA amplification and confirmation of generated LAMP products by sequencing. Vet. Parasitol. 158, 11-22. https://doi.org/10.1016/j. vetpar.2008.09.012

Baranwal VK, Singh J, Ahlawat YS, Gopal K, Charaya MU (2005): Citrus yellow mosaic virus is associated with mosaic disease in Rangpur lime rootstock of citrus. Curr. Sci. 89, 1596-1599.

Borah BK, Johnson AMA, Gopal DVRS, Dasgupta I (2008): A comparison of four DNA extraction methods for the detection of Citrus yellow mosaic Badnavirus from two species of citrus using PCR and dot-blot hybridization. J. Virol. Methods 151, 321-324. https://doi.org/10.1016/j. jviromet.2008.05.022
Euler M, Wang Y, Heidenreich D, Patel P, Strohmeier O, Hakenberg S, Niedrig M, Hufert FT, Weidmann M (2013): Development of a panel of recombinase polymerase amplification assays for detection of biothreat agents. J. Clin. Microbiol. 51, 1110-1117. https://doi.org/10.1128/ LCM.02704-12

Kapoor R, Srivastava N, Kumar S, Saritha RK, Sharma SK, Jain RK, Baranwal VK (2017): Development of a recombinase polymerase amplification assay for the diagnosis of banana bunchy top virus in different banana cultivars. Arch. Virol. 162, 2791-2796. https://doi.org/10.1007/ s00705-017-3399-9

King AMQ, Adams MJ, Carstens EB, Lefkowitz EJ (2012): Virus taxonomy: classification and nomenclature of viruses. In Ninth Report of the International Committee on Taxonomy of Viruses. Elsevier Academic Press, San Diego, CA, pp. 385-388.

Korsten LG, Sanders HJSu, Garnier M, Bove JM, Kotze JM (1993): Detection of citrus greening- infected citrus in South Africa using a DNA probe and monoclonal antibodies, In. Proc 12th Conference IOCV : IOCV, Riverside, California, pp. 224-234.

Kumar PV, Sharma SK, Rishi N, Baranwak VK (2018): Efficient immunodiagnosis of Citrus yellow mosaic virus using polyclonal antibodies with an expressed recombinant virion-associated protein. 3 Biotech. 8, 1-7. https://doi. org/10.1007/s13205-017-1063-4

Londono MA, Harmon CL, Polston JE (2016): Evaluation of recombinase polymerase amplification for detection of begomoviruses by plant diagnostic clinics. Virol. J. 13, 48.

Mekuria TA, Zhang S, Eastvella KC (2014): Rapid and sensitive detection of Little cherry virus 2 using isothermal reverse transcription-recombinase polymerase amplification. J. Virol. Methods 205, 24-30.

Pipenburg O, Williams CH, Stemple DL, Armes NA (2006): DNA detection using recombination proteins. PLoS Biol. 4, 1115-1121. https://doi.org/10.1371/journal. pbio.0040204

Silva G, Bomer M, Nkere C, Kumar PL, Seal SE (2015): Rapid and specific detection of Yam mosaic virus by reversetranscription recombinase polymerase amplification. J. Virol. Methods 222, 138-144. https://doi.org/10.1016/j. jviromet.2015.06.011

Zhang S, Ravelonandro M, Russell P, McOwen N, Briard P, Bohannon S, Vrient A (2014): Rapid diagnostic detection of Plum pox virus in Prunus plants by isothermal AmplifyRP ${ }^{\oplus}$ using reverse transcription-recombinase polymerase amplification. J. Virol. Methods 207, 114-120. https://doi.org/10.1016/j.jviromet.2014.06.026 